\title{
Development and Validation of an LC-MS/MS Based Method for the Determination of Deoxynivalenol and Its Modified Forms in Maize
}

\author{
Iris Fiby ${ }^{1}$, Marta Magdalena Sopel ${ }^{1}$, Herbert Michlmayr ${ }^{2} \mathbb{D}$, Gerhard Adam ${ }^{2} \mathbb{D}$ and Franz Berthiller ${ }^{1, *(\mathbb{D})}$ \\ 1 Institute of Bioanalytics and Agro-Metabolomics, Department of Agrobiotechnology (IFA-Tulln), \\ University of Natural Resources and Life Sciences, Vienna (BOKU), Konrad Lorenz Str. 20, \\ 3430 Tulln, Austria; iris.fiby@gmail.com (I.F.); marta_magdalena@onet.eu (M.M.S.) \\ 2 Institute of Microbial Genetics, Department of Applied Genetics and Cell Biology, BOKU, \\ Konrad Lorenz Str. 24, 3430 Tulln, Austria; herbert.michlmayr@boku.ac.at (H.M.); \\ gerhard.adam@boku.ac.at (G.A.) \\ * Correspondence: franz.berthiller@boku.ac.at; Tel.: +43-1-47654-97371
}

Citation: Fiby, I.; Sopel, M.M.; Michlmayr, H.; Adam, G.; Berthiller, F. Development and Validation of an LC-MS/MS Based Method for the Determination of Deoxynivalenol and Its Modified Forms in Maize. Toxins 2021, 13, 600. https://doi.org/ $10.3390 /$ toxins 13090600

Received: 28 June 2021

Accepted: 25 August 2021

Published: 27 August 2021

Publisher's Note: MDPI stays neutral with regard to jurisdictional claims in published maps and institutional affiliations.

Copyright: (C) 2021 by the authors. Licensee MDPI, Basel, Switzerland. This article is an open access article distributed under the terms and conditions of the Creative Commons Attribution (CC BY) license (https:/ / creativecommons.org/licenses/by/ $4.0 /)$.

\begin{abstract}
The Fusarium mycotoxin deoxynivalenol (DON) is a common contaminant of cereals and is often co-occurring with its modified forms DON-3-glucoside (D3G), 3-acetyl-DON (3ADON) or 15acetyl-DON (15ADON). A stable-isotope dilution liquid chromatography-tandem mass spectrometry (LC-MS/MS) based method for their determination in cereals was developed and validated for maize. Therefore, ${ }^{13} \mathrm{C}$-labelled D3G was enzymatically produced using ${ }^{13} \mathrm{C}$-DON and $\left[{ }^{13} \mathrm{C}_{6} \mathrm{Glc}\right]-$ sucrose and used as an internal standard (IS) for D3G, while uniformly ${ }^{13} \mathrm{C}$ labelled IS was used for the other mycotoxins. Baseline separation was achieved for the critical peak pair DON/D3G, while $3 \mathrm{ADON} / 15 \mathrm{ADON}$ could not be fully baseline separated after testing various reversed phase, fluorinated phase and chiral LC columns. After grinding, weighing and extracting the cereal samples, the raw extract was centrifuged and a mixture of the four ${ }^{13} \mathrm{C}$-labelled ISs was added directly in a microinsert vial. The subsequent analytical run took $7 \mathrm{~min}$, followed by negative electrospray ionization and selected reaction monitoring on a triple quadrupole MS. Maize was used as a complex cereal model matrix for validation. The use of the IS corrected the occurring matrix effects efficiently from 76 to $98 \%$ for D3G, from 86 to $103 \%$ for DON, from 68 to $100 \%$ for $15 \mathrm{ADON}$ and from 63 to $96 \%$ for $3 \mathrm{ADON}$.
\end{abstract}

Keywords: mycotoxins; trichothecenes; masked mycotoxins; modified mycotoxins; mass spectrometry; stable-isotope dilution assay

Key Contribution: A novel highly accurate liquid chromatography-tandem mass spectrometry method for the determination of deoxynivalenol and its modified forms was developed and validated for maize.

\section{Introduction}

Mycotoxins are low molecular weight, secondary metabolites of fungi of different genera, which may cause serious health implications for mammals, when ingested with food or feed, as reviewed by [1]. One of the most prevalent groups of mycotoxins - trichothecenescontains a tetracyclic sesquiterpenoid 12,13-epoxytrichothec-9-en ring structure, with the epoxide group responsible for the typical trichothecenes' toxic effects, as reviewed by [2]. Trichothecenes are produced by plant pathogenic Fusarium spp., growing preferably on cereals in the field at temperate climates [3]. The type B trichothecene deoxynivalenol (DON) is one of the most commonly found mycotoxins worldwide [4]. Its toxic effects include emesis (hence, its colloquial name "vomitoxin"), anorexia, growth retardation, immunotoxicity, impaired reproduction and development, altered neuroendocrine signaling, proinflammatory gene induction and altered gut integrity [5]. 
DON is often co-occurring with its acetylated biosynthetical precursors 3-acetyl-DON (3ADON) or 15-acetyl-DON (15ADON), and its plant metabolite DON-3-glucoside (D3G, Figure 1) in cereals, such as wheat, barley, oats, rye and maize or products thereof (e.g., [6,7]). As both the acetylated and the glucosidic forms of DON can be easily hydrolyzed to DON in vivo [8], the toxicity of those so-called "modified mycotoxins" [9] is basically the same as that of the DON for humans. As such, the European Food Safety Authority proposed a group tolerable daily intake value of $1 \mu \mathrm{g} / \mathrm{kg}$ bodyweight for the sum of the four compounds [10].

(a)

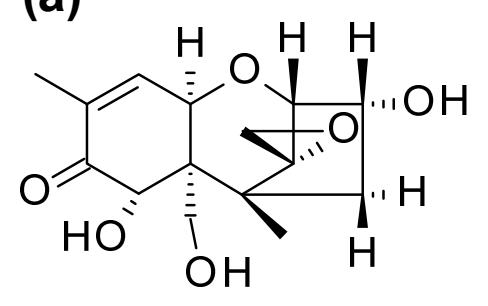

(c)

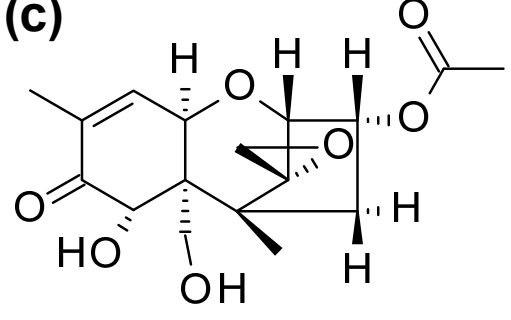

(b)

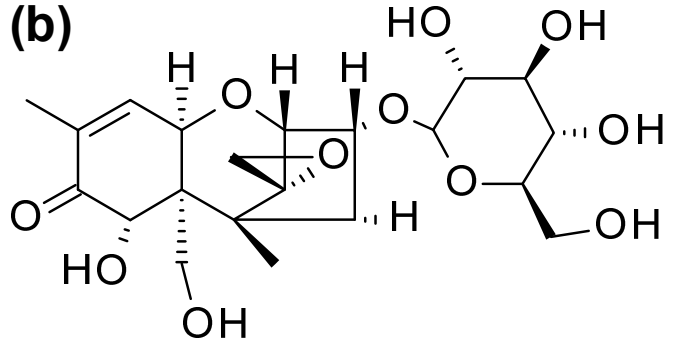

(d)

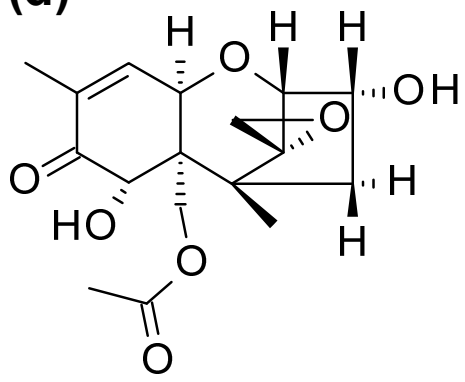

Figure 1. Chemical structures of (a) deoxynivalenol (DON) and its modified forms (b) deoxynivalenol-3-glucoside (D3G), (c) 3-acetyldeoxynivalenol (3ADON) and (d) 15-acetyldeoxynivalenol (15ADON).

The most popular technique to determine mycotoxins in food nowadays [11,12] is liquid chromatography coupled to mass spectrometry (LC-MS). Typically reversed phase chromatography on a C-18 column is used to separate mycotoxins of different polarities, before they are charged during electrospray ionization and subsequently analyzed with MS [13]. LC-MS offers tremendous sensitivity, selectivity and multiplexing capability, but accurate quantification is often challenged due to matrix effects [14]. As such, coeluting matrix compounds suppress or enhance the signal (SSE), compared to standards in neat solvents (external calibration). One of the most sophisticated ways to cope with matrix effects is the usage of stable isotope labeled internal standards. Those have the same physico-chemical properties as the analytes, but different molecular masses and do not occur in nature. Several stable isotope dilution assays (SIDA) have been developed for accurate mycotoxin determination so far, including the most important mycotoxins (e.g., [15-17]). While uniformly labeled ${ }^{13} \mathrm{C}-\mathrm{DON},{ }^{13} \mathrm{C}-3 \mathrm{ADON}$ and ${ }^{13} \mathrm{C}-15 \mathrm{ADON}$ are commercially available, until very recently, ${ }^{13} \mathrm{C}-\mathrm{D} 3 \mathrm{G}$ was not. Habler et al. proposed the Königs-Knorr method to chemically synthesize DON-3-[ $\left[{ }^{13} \mathrm{C}_{6}\right]$-glucoside from unlabeled DON and $\left[{ }^{13} \mathrm{C}_{6}\right]$-labeled glucose. The authors successfully applied the compound as IS for the analysis of beer samples for the concurrent determination of DON and D3G [18].

Another challenge in mass spectrometry is the determination of isomers, as they-by definition-share the same molecular formula and mass. If specific MS/MS fragmentation is unavailable, chromatographic separation should be aimed for. In the case of 3ADON and $15 \mathrm{ADON}$, this separation is hard to achieve and in many multi-toxin methods, those two compounds co-elute (e.g., [19]). While the loss of a $\mathrm{CH}_{2} \mathrm{O}$ group at $\mathrm{C}-15$ during collision 
induced dissociation in MS/MS allows the formation of a specific fragment of 3ADON in negative ion mode $(m / z 307)$, no such specific ion is available for 15ADON, severely limiting its quantification.

The major aim of this work was to develop and validate a robust, fast and accurate LC-MS/MS based method that allows the concurrent determination of DON along with its major modified forms 3ADON, 15ADON and D3G. We enzymatically produced and purified uniformly labeled ${ }^{13} \mathrm{C}$-D3G and used it together with ${ }^{13} \mathrm{C}-\mathrm{DON},{ }^{13} \mathrm{C}-3 \mathrm{ADON}$ and ${ }^{13} \mathrm{C}-15 \mathrm{ADON}$ as internal standards. Chromatographic separation was optimized, allowing near base-line separation of 3ADON and 15ADON. To the best of our knowledge, this is the first stable-isotope dilution assay covering those four mycotoxins.

\section{Results}

\subsection{MS Method Optimization}

One of the main prerequisites to developing a SIDA method was the production of ${ }^{13} \mathrm{C}-\mathrm{D} 3 \mathrm{G}$, which was commercialized later. U- $\left[{ }^{13} \mathrm{C}_{21}\right]-\mathrm{D} 3 \mathrm{G}$ was synthesized in a batch conversion containing $100 \mathrm{mg}{ }^{13} \mathrm{C}$-DON. The batch contained $21 \mathrm{mM} \mathrm{U}-\left[{ }^{13} \mathrm{C}_{15}\right]-\mathrm{DON}$, $32 \mathrm{mM}\left[{ }^{13} \mathrm{C}_{6} \mathrm{Glc}\right]$-sucrose ( $\beta$-D-fructofuranosyl- $\alpha$-D-[U- ${ }^{13} \mathrm{C}_{6}$ ]glucopyranoside; 99 atom \% ${ }^{13} \mathrm{C}$, Omicron Biochemicals Inc., South Bend, IN, USA), 1 mM UDP, $100 \mathrm{mM}$ potassium phosphate $\mathrm{pH}$ 7. UDP-glucosyltransferase OsUGT79 and sucrose synthase AtSUS1 [20] were added at $1.5 \mathrm{mg} / \mathrm{mL}$ each. The reaction was incubated at $37^{\circ} \mathrm{C}$. After $48 \mathrm{hrs}$, the batch contained less than $0.5 \%$ un-conjugated DON. U- $\left[{ }^{13} \mathrm{C}_{21}\right]$-D3G was isolated by preparative HPLC (Agilent 1100 series, Waldbronn, Germany) and freeze-dried. The total yield was $76 \%$.

The electrospray (ESI) MS/MS fragmentation spectra of the produced compound, as well as those of unlabeled D3G at $30 \mathrm{eV}$ collision energy, are shown in Figure 2. All major fragments of D3G were found with ${ }^{13} \mathrm{C}-\mathrm{D} 3 \mathrm{G}$ with the according mass shifts $(+21$ amu for the precursor due the sum formula of $\mathrm{C}_{21} \mathrm{H}_{30} \mathrm{O}_{11}$ ). One of the main fragments is the loss of a $\mathrm{CH}_{2} \mathrm{O}$ group from the $\mathrm{C}-15$ backbone of $\mathrm{DON}(\mathrm{m} / \mathrm{z} 427$ or 447 for the labeled compound). Despite the same collision energy, that fragment was more abundant than the deprotonated precursor of ${ }^{13} \mathrm{C}$-D3G, but less abundant using the deprotonated D3G as precursor for reasons unknown. However, the acetate adduct resulted in much higher overall intensities and the fragmentation pattern of D3G and of ${ }^{13} \mathrm{C}-\mathrm{D} 3 \mathrm{G}$ were virtually identical.

Consecutive syringe pump optimization was performed for all analytes and IS for both the acetate adducts and the deprotonated precursors and used for method development. After coupling with LC, it could be seen that the acetate adducts of all analytes gave higher signal to noise ratios; hence, three transitions for each analyte-always using the $\left[\mathrm{M}+\mathrm{CH}_{3} \mathrm{COO}\right]^{-}$precursors-were selected for the final method (Table 1 ). The entrance potentials were kept at $10 \mathrm{~V}$ for each transition. Dwell times of $20 \mathrm{~ms}$ and pause times of $5 \mathrm{~ms}$ between transitions resulted in a cycle time of $0.45 \mathrm{~s}$.
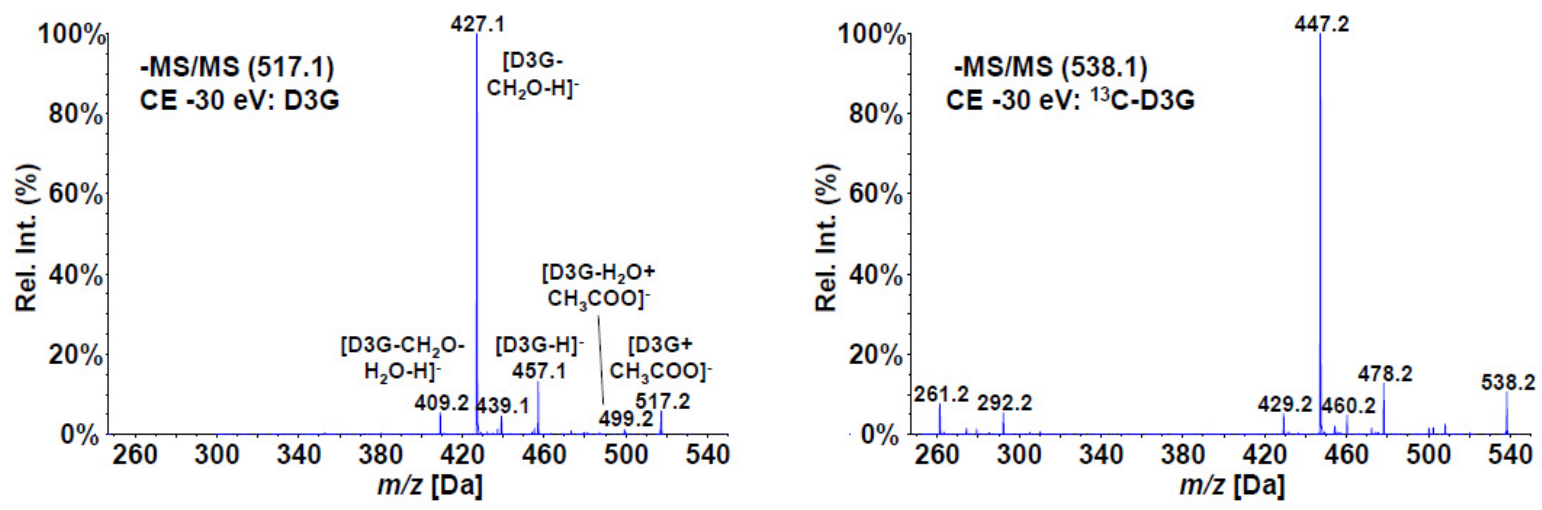

Figure 2. Cont. 

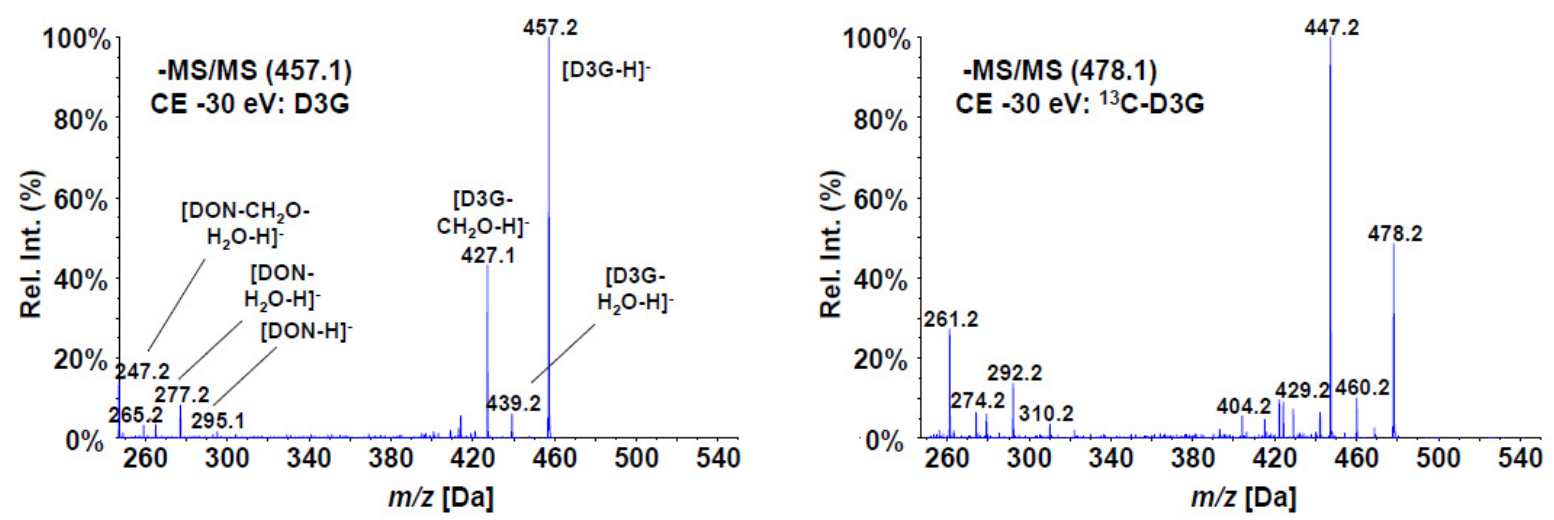

Figure 2. Enhanced Product Ion (MS/MS) spectra of D3G (left) and ${ }^{13}$ C-D3G (right) at a collision energy of $30 \mathrm{eV}$. The spectra derived from the acetate adducts are shown on top, the spectra using the deprotonated precursors on the bottom.

Table 1. List of analytes with optimized ESI-MS/MS parameters.

\begin{tabular}{|c|c|c|c|c|c|}
\hline Analyte ID & Q1 Mass (Da) & Q3 Mass (Da) & $\mathrm{DP}(\mathrm{V})$ & $\mathrm{CE}(\mathrm{eV})$ & CXP (V) \\
\hline D3G 1 & 517.1 & 457.1 & -80 & -22 & -7 \\
\hline D3G IS 1 & 538.1 & 478.1 & -80 & -22 & -7 \\
\hline D3G 2 & 517.1 & 59.0 & -80 & -74 & -9 \\
\hline D3G IS 2 & 538.1 & 59.0 & -80 & -74 & -9 \\
\hline D3G 3 & 517.1 & 427.0 & -80 & -32 & -5 \\
\hline D3G IS 3 & 538.1 & 447.0 & -80 & -32 & -5 \\
\hline DON 1 & 355.0 & 59.0 & -70 & -36 & -9 \\
\hline DON IS 1 & 370.0 & 59.0 & -70 & -36 & -9 \\
\hline DON 2 & 355.0 & 295.0 & -70 & -16 & -13 \\
\hline DON IS 2 & 370.0 & 310.0 & -70 & -16 & -13 \\
\hline DON 3 & 355.0 & 265.0 & -70 & -24 & -13 \\
\hline DON IS 3 & 370.0 & 279.0 & -70 & -24 & -13 \\
\hline ADONs 1 & 397.1 & 59.0 & -70 & -34 & -9 \\
\hline ADON IS 1 & 414.1 & 49.0 & -70 & -34 & -9 \\
\hline ADONs 2 & 397.1 & 337.1 & -70 & -12 & -7 \\
\hline ADON IS 2 & 414.1 & 354.1 & -70 & -12 & -7 \\
\hline 3ADON & 397.1 & 307.0 & -70 & -22 & -5 \\
\hline 3ADON IS & 414.1 & 323.0 & -70 & -22 & -5 \\
\hline
\end{tabular}

D3G deoxynivalenol-3-glucoside, DON deoxynivalenol, ADONs acetyl-deoxynivalenols, 3ADON 3-acetyldeoxynivalenol, IS internal standard, DP declustering potential, CE collision energy, CXP cell exit potential.

\subsection{LC Method Optimization}

Different types of chromatography (reversed phased, chiral) and 13 different columns (including C18 and pentafluorophenyl phases) were evaluated to separate the critical peak pairs of DON/D3G and 3ADON/15ADON. Ammonium acetate $(2 \mathrm{mM})$ was added into both mobile phases to ensure acetate ion adduct formation in negative ESI mode. With all conditions, acetonitrile (ACN) gave better separation for 3ADON/15ADON than methanol $(\mathrm{MeOH})$ and was therefore chosen as the organic solvent for the final method. For DON/D3G, separation was similar for both mobile phases. The retention times and resolutions of the critical peak pairs for the tested columns, using the ACN mobile phase, are summarized in Table 2. 
Table 2. Evaluated analytical columns for the LC-MS/MS method.

\begin{tabular}{|c|c|c|c|c|c|c|c|}
\hline Column & $\begin{array}{l}t_{R}(D O N) \\
\quad(\min )\end{array}$ & $\begin{array}{l}t_{R}(\mathrm{D} 3 G) \\
(\min )\end{array}$ & $\begin{array}{c}t_{R}(3 A D O N) \\
(\min )\end{array}$ & $\begin{array}{c}t_{R}(15 A D O N) \\
(\min )\end{array}$ & $\begin{array}{l}\text { FWHM } \\
\text { (min) }\end{array}$ & $\begin{array}{c}R_{S} \\
\text { (DON/D3G) }\end{array}$ & $\begin{array}{c}\mathrm{R}_{\mathrm{S}} \\
\text { (3/15ADON) }\end{array}$ \\
\hline $\begin{array}{c}\text { Agilent Zorbax Eclipse } \\
\text { Plus }\end{array}$ & 2.63 & 2.68 & 4.16 & 4.17 & 0.045 & -1.11 & -0.22 \\
\hline $\begin{array}{l}\text { Agilent Zorbax } \\
\text { Extend-C18 }\end{array}$ & 2.15 & 2.26 & 3.85 & 3.86 & 0.077 & -1.43 & -0.13 \\
\hline $\begin{array}{c}\text { Agilent Poroshell } \\
\text { EC-C18 }\end{array}$ & 5.30 & 5.14 & 7.30 & 7.16 & 0.057 & 2.82 & 2.47 \\
\hline Agilent Zorbax SB C18 & 5.87 & 5.87 & 9.00 & 9.02 & 0.085 & 0.00 & -0.24 \\
\hline $\begin{array}{l}\text { Agilent Zorbax } \\
\text { XDB-C18 }\end{array}$ & 4.75 & 4.52 & 6.58 & 6.46 & 0.060 & 3.83 & 2.00 \\
\hline Daicel Chiralcel & 3.59 & 3.45 & 11.00 & 9.00 & 3.000 & 0.05 & 0.67 \\
\hline Daicel Chiralpak & 2.29 & 2.06 & 9.29 & 9.08 & 0.143 & 1.60 & 1.47 \\
\hline $\begin{array}{l}\text { Phenomenex Kinetex } \\
\text { C18 }\end{array}$ & 4.07 & 4.03 & 5.81 & 5.82 & 0.075 & 0.53 & -0.13 \\
\hline Phenomenex Kinetex F5 & 4.26 & 4.15 & 6.33 & 6.23 & 0.067 & 1.65 & 1.50 \\
\hline Sigma Discovery HS F5 & 6.14 & 5.95 & 9.88 & 9.68 & 0.122 & 1.56 & 1.64 \\
\hline Thermo Hypersil Gold & 1.84 & 2.13 & 3.68 & 3.69 & 0.112 & -2.60 & -0.09 \\
\hline $\begin{array}{l}\text { Waters Acquity BEH } \\
\text { C18 }\end{array}$ & 2.98 & 3.21 & 4.37 & 4.40 & 0.040 & -5.75 & -0.75 \\
\hline $\begin{array}{c}\text { Waters Acquity HSS T3 } \\
\text { C18 }\end{array}$ & 5.20 & 4.93 & 7.17 & 7.02 & 0.052 & 5.23 & 2.90 \\
\hline
\end{tabular}

$t_{R}$ retention time, FWHM full width half maximum, Rs resolution. A water-acetonitrile gradient ( $5 \% \rightarrow 60 \%$ acetonitrile in 9 min) containing $2 \mathrm{mM}$ ammonium acetate was used for separation. The flow rate was 0.2 or $0.4 \mathrm{~mL} / \mathrm{min}$, depending on the column length.

Only three columns (marked bold in Table 2) yielded resolutions $\geq 2.0$ for both peak pairs. Of those, the Waters Acquity HSS T3 yielded the highest separation power and was used for further optimization. The gradient was optimized and the run time shortened to develop the final method (see chromatogram in Figure 3).

\subsection{Method Validation}

Prior to method validation, different extraction solvents $(20 \%, 50 \%, 80 \%$ aqueous $A C N)$ were tested. All three solvents yielded almost identical apparent recoveries $\left(R_{A}\right)$. As expected, the matrix effects (SSE) were slightly less pronounced with more apolar solvents, while the extraction recoveries $\left(\mathrm{R}_{\mathrm{E}}\right)$ were slightly higher with more polar solvents (data not shown). As the matrix effects are supposed to be corrected by the IS, $\mathrm{ACN} / \mathrm{H}_{2} \mathrm{O}, 20 / 80$ $(v / v)$ was chosen as extraction solvent. In addition, this yielded the advantage that the raw solvent can be directly injected into the LC-MS/MS system without causing peak distortion.

The determined method performance parameters for maize include apparent recovery $\left(\mathrm{R}_{\mathrm{A}}\right)$, matrix effects (SSE) and extraction recovery $\left(\mathrm{R}_{\mathrm{E}}\right)$ and are summarized in Table 3. For limits of quantification (LOQ) determination, the spiked maize samples were used which consistently yielded signal to noise ratios exceeding 10 . Linearity has been shown for neat standard solutions in the range of 3-1000 $\mu \mathrm{g} / \mathrm{L}$ (equaling 12-4000 $\mu \mathrm{g} / \mathrm{kg}$ ) with squared linear calibration coefficients exceeding 0.998 for all analytes. 


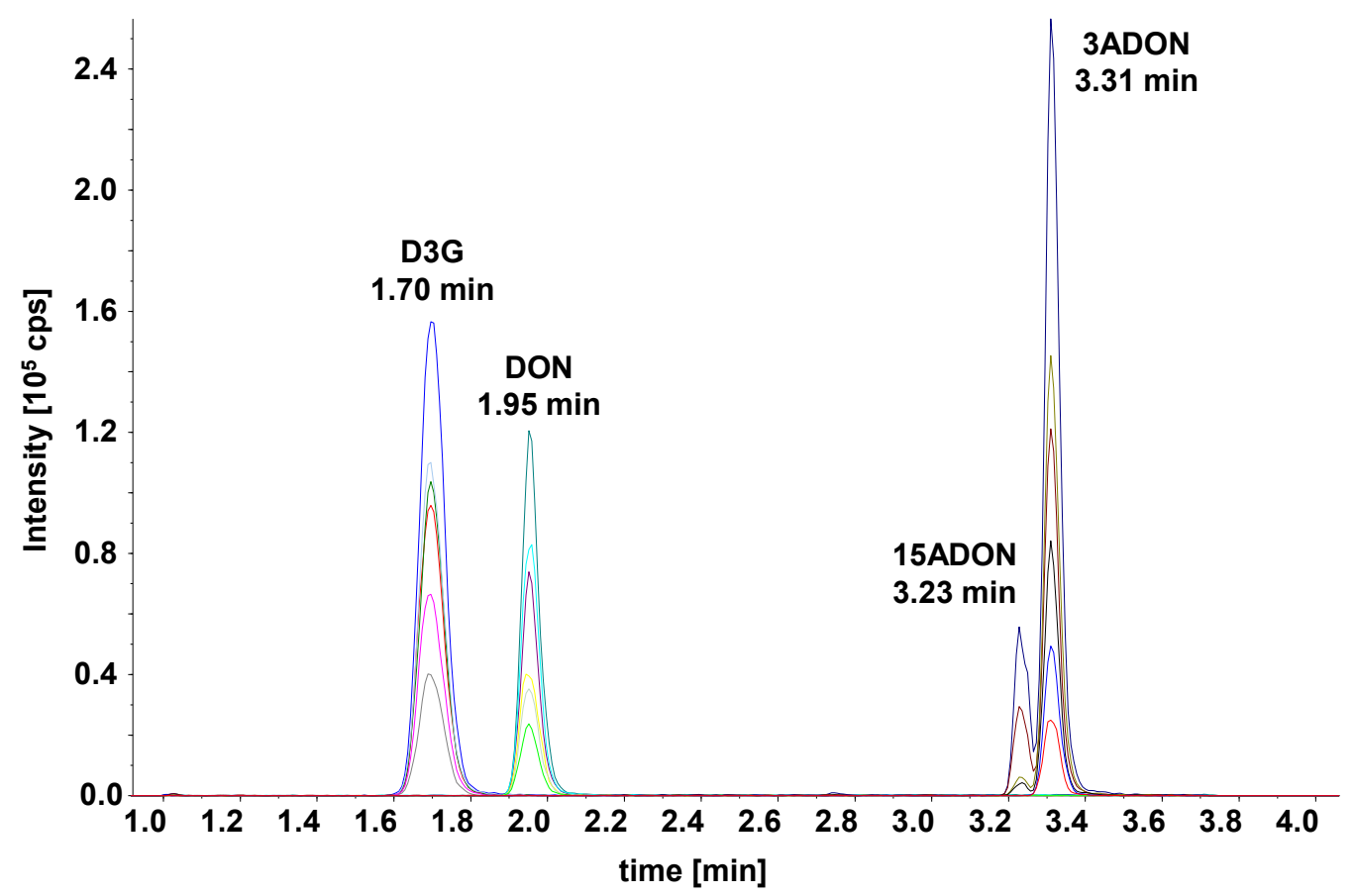

Figure 3. LC-MS/MS selected ion monitoring (SRM) chromatogram of the optimized method. Separation was achieved on a Waters Acquity UPLC HSS T3 C18, $1.8 \mu \mathrm{m}, 2.1 \times 100 \mathrm{~mm}$ column using a water-acetonitrile gradient.

Table 3. Method performance parameters.

\begin{tabular}{|c|c|c|c|c|c|c|}
\hline Analyte & LOQ Solution $(\mu \mathrm{g} / \mathrm{L})$ & LOQ Maize ( $\mu \mathrm{g} / \mathrm{kg})$ & $R_{E}(\%)$ & SSE (\%) & $R_{A}(\%)$ & RSDr (\%) \\
\hline D3G (ext.) & \multirow{2}{*}{$<10$} & \multirow{2}{*}{$<40$} & \multirow{2}{*}{94.7} & 75.9 & \multirow{2}{*}{92.3} & 3.1 \\
\hline D3G (int.) & & & & 97.5 & & 8.3 \\
\hline DON (ext.) & \multirow{2}{*}{$<10$} & \multirow{2}{*}{$<40$} & \multirow{2}{*}{101} & 86.4 & \multirow{2}{*}{104} & 5.9 \\
\hline DON (int.) & & & & 103 & & 5.3 \\
\hline 15ADON (ext.) & \multirow{2}{*}{$<30$} & \multirow{2}{*}{$<120$} & \multirow{2}{*}{105} & 67.8 & \multirow{2}{*}{105} & 9.4 \\
\hline 15ADON (int.) & & & & 100 & & 7.8 \\
\hline 3ADON (ext.) & \multirow{2}{*}{$<10$} & \multirow{2}{*}{$<40$} & \multirow{2}{*}{94.4} & 63.2 & \multirow{2}{*}{90.8} & 7.0 \\
\hline 3ADON (int.) & & & & 96.2 & & 5.7 \\
\hline
\end{tabular}

LOQ: limit of quantification; $\mathrm{R}_{\mathrm{E}}$ : extraction recovery; SSE: signal suppression or enhancement; $\mathrm{R}_{\mathrm{A}}$ : apparent recovery; RSDr: relative standard deviation under conditions of repeatability; ext. external calibration; int. internal calibration.

\section{Discussion}

Our aim was to develop a robust yet accurate, fast and easy to use LC-MS/MS based method for the determination of DON and its major metabolites for routine food analysis. In order to do so, it was first imperative to produce and characterize ${ }^{13} \mathrm{C}-\mathrm{D} 3 \mathrm{G}$, which is now available to all stakeholders. The applied enzymatic strategy [20] can be easily scaled up and yielded uniformly labelled ${ }^{13} \mathrm{C}_{21}$-D3G for the first time, already using ${ }^{13} \mathrm{C}_{15}$-DON [15] as starting compound.

Another-often ignored-issue in mycotoxin determination was partly solved with the accurate quantification of 3ADON and 15ADON. The two compounds can be easily separated using gas chromatography [21], but barely using LC even by applying long run-times [22]. Fusarium spp. originally produce 3,15-diacetyl-DON that in the final step of biosynthesis is deacetylated by an esterase encoded by the TRI8 gene [2]. Different alleles of this gene determine production of either 3ADON or 15ADON chemotypes in $F$. graminearum. While often samples are only contaminated with one chemotype, e.g., com- 
plex food samples or mixed feedstuffs easily can contain both acetylated forms. For a toxicological point of view, it is important to differ between the compounds, as there are some differences in gastro-intestinal deleterious effects and relative toxicity, with 15ADON often being the more potent toxin [8]. From an analytical-chemical point of view, it is relevant to observe differences in ionization of the compounds (see Figure 3), so a sum value with either or both toxins, as standards will lead to inaccurate quantification when there is no chromatographical separation. Multi-mycotoxin methods based on LC-MS/MS are widely used nowadays [11,12], but remain a compromise in various aspects in order to "squeeze in" a multitude of analytes in a single method. In case accurate quantification of 3ADON and 15ADON is warranted, methods not resolving the compounds cannot be recommended. Due to the specific fragmentation of 3ADON, this compound can be accurately determined even in the presence of 15ADON with such methods, e.g., [19]. While this proposed method does not fully solve the issue, the separation of 3ADON and $15 A D O N$ is sufficient to accurately quantify them. While we used the peak areas for the quantification (due to only low crosstalk from the overlapping peaks), a suitable option would be to use the peak heights instead (after using the same peak smoothing settings for all samples and standards).

Several different extraction solvents were tested in this study. In (multi-analyte) mycotoxin determination, a very common solvent is $\mathrm{ACN} / \mathrm{H}_{2} \mathrm{O} /$ acetic acid $(79 / 20 / 1$, $v / v / v$ ) [19]. Acidification is important for the extraction of several (charged) mycotoxins, but not for type B-trichothecenes, e.g., [21,22]. The high ratio of organic solvent usually serves multiple purposes: (a) more apolar mycotoxins than type B-trichothecenes can be extracted, (b) the solvent is compatible with several clean-up strategies and (c) fewer polar matrix compounds are co-extracted, yielding fewer matrix effects for polar analytes. Considering compensation of matrix effects by the used ISs, we opted for the solvent composition with the highest extraction recoveries, which was $\mathrm{ACN} / \mathrm{H}_{2} \mathrm{O}, 20 / 80(v / v)$. Choosing this solvent also allows direct injection in the UHPLC system after the addition of ISs and avoids a further dry-down step.

More sensitive methods for the determination of type B-trichothecenes are available in literature, recently reviewed in [23]. Such methods often need a clean-up and concentration step, which could be avoided here. Sample preparation is not only faster and cheaper (even considering the costs of the ISs), but less error-prone and more robust. This was made possible by the use of a highly sensitive MS system. In case such a system is unavailable, up-concentration is a requirement to achieve suitable limits of quantification. Mass spectrometric performance varies from day to day, and in the worst case, also during measurement. The use of standards before, after and in the middle of the sequence is therefore recommended. We did notice only a negligible decrease of the slopes of the individual calibration curves during a batch, allowing us to use all replicates for the evaluation of the results. We did, however, notice day-to-day variations in sensitivity, as the instrument is used by multiple users and running different methods (and matrices). As such, we refrained from the determination of limits of detections, which is often performed under optimal system performance. Instead, we used standards with concentrations of 3 , $10,30,100 \mu \mathrm{g} / \mathrm{L}$ and defined the LOQ for that level which always showed signal/noise ratios higher than 10. This approach resulted in LOQs of $10 \mu \mathrm{g} / \mathrm{L}(40 \mu \mathrm{g} / \mathrm{kg})$ for all analytes, but the rather poorly ionizing 15ADON (LOQ $30 \mu \mathrm{g} / \mathrm{L}$ or $120 \mu \mathrm{g} / \mathrm{kg}$ ). With maximum regulated levels of $200-1750 \mu \mathrm{g} / \mathrm{kg}$ for DON in Europe [24], we consider the method sensitive enough for routine applications. In case low background levels are the study subject, an intermediate up-concentration step would be required.

On purpose, we added the ISs only after extraction, only compensating matrix effects during measurements and random injection volume variations. The use of conical microinserts allows minimizing the amount of ISs, thus saving costs. Unconventionally, we also opted to simply dilute $80 \mu \mathrm{L}$ of raw extracts with $20 \mu \mathrm{L}$ of ISs in the vials-resulting in a dilution factor for the samples. However, this factor is offset if the standards are prepared in the same manner. For example, $80 \mu \mathrm{L}$ of a $100 \mu \mathrm{g} / \mathrm{L}$ neat standard solution 
are diluted with $20 \mu \mathrm{L}$ of ISs, but further regarded as $100 \mu \mathrm{g} / \mathrm{L}$ standard (despite its actual concentration of only $80 \mu \mathrm{g} / \mathrm{L}$ ). Using this little trick, no back calculations (other than the dilution factor of four for extraction) are needed for data evaluation.

It is sometimes believed that the repeatability of a method could always be improved using ISs. In our case, which is in agreement with current literature, e.g., [16,17], this was not the case. Already excellent RSDr values of 3-9\% for all analytes using external calibration changed to 5-8\% using internal calibration. Expected interlaboratory reproducibilies $\mathrm{RSD}_{\mathrm{R}}$ of $32.0 \%, 22.6 \%$ and $16.0 \%$ for levels of 10,100 and $1000 \mu \mathrm{g} / \mathrm{kg}$, according to [25], are likely to be reached. Thus, even further improvement of the method precision by using IS was unlikely and not obtained.

Concluding, the presented method offers a robust manner to accurately determine DON and its major metabolites in cereals, using minimal sample preparation if a highly sensitive LC-MS/MS system is available.

\section{Materials and Methods}

\subsection{Chemicals}

Acetonitrile (ACN, gradient grade) was purchased from VWR International GmbH (Vienna, Austria), methanol ( $\mathrm{MeOH}, \geq 99.9 \%$ ) was obtained from Honeywell (Seelze, Germany), ammonium acetate (LC-MS grade) was provided by Sigma Aldrich (Vienna, Austria). Ultrapure water was produced by an ELGA Purelab Ultra system (Celle, Germany). All standards were provided by Romer Labs GmbH (Tulln, Austria). The individual stock standard solutions (all in ACN) had the following concentrations: DON $100.5 \mu \mathrm{g} / \mathrm{mL}, 3 A D O N 100.4 \mu \mathrm{g} / \mathrm{mL}, 15 A D O N 100.1 \mu \mathrm{g} / \mathrm{mL}, \mathrm{D} 3 \mathrm{G} 50.4 \mu \mathrm{g} / \mathrm{mL}, \mathrm{U}-\left[{ }^{13} \mathrm{C}_{15}\right]-$ DON $25.1 \mu \mathrm{g} / \mathrm{mL}\left(99.0\right.$ atom\% $\left.{ }^{13} \mathrm{C}\right), \mathrm{U}-\left[{ }^{13} \mathrm{C}_{17}\right]-3 \mathrm{ADON} 25.2 \mu \mathrm{g} / \mathrm{mL}\left(99.4\right.$ atom\% $\left.{ }^{13} \mathrm{C}\right)$, $\mathrm{U}-\left[{ }^{13} \mathrm{C}_{17}\right]$-15ADON $10.0 \mu \mathrm{g} / \mathrm{mL}\left(99.1 \%{ }^{13} \mathrm{C}\right)$. U-[ $\left.{ }^{13} \mathrm{C}_{21}\right]-\mathrm{D} 3 \mathrm{G}$ became recently available from Romer Labs $\left(10.6 \mu \mathrm{g} / \mathrm{mL}, 99.2\right.$ atom $\left.\%{ }^{13} \mathrm{C}\right)$.

\subsection{Samples}

Different maize samples (1 kg each) used for the method development were bought at a health food store in Tulln, Austria, and milled with a Romer Analytical Sampling Mill from Romer Labs GmbH (Getzersdorf, Austria). For the determination of natural mycotoxin contamination, samples were extracted and measured with a multi-mycotoxin method [19]. A popcorn maize from controlled organic cultivation (Rapunzel Naturkost, Germany) was shown to be uncontaminated with 3ADON, 15ADON and D3G and was used as a blank for method validation. DON was only found in traces, below the LOQ of the used method $(<10 \mu \mathrm{g} / \mathrm{kg})$.

\subsection{LC-MS/MS Optimization}

All LC-MS/MS measurements were performed on a 1290 series ultra-high performance liquid chromatography system (Agilent Technologies, Waldbronn, Germany) coupled to a QTrap 6500+ MS/MS System (Sciex, Foster City, CA, USA) equipped with a IonDrive Turbo V electrospray ionization (ESI) source. Analysis was carried out using the dynamic selective reaction monitoring mode (SRM) with monitoring of two transitions (quantifier and qualifier).

Precursor and product ion selection as well as the optimization of declustering potentials (DP), entrance potentials (EP), collision energies (CE) and cell exit potentials (CXP) were performed with flow injection of single analyte solutions of $1 \mathrm{mg} / \mathrm{L}$ concentration using a Hamilton syringe and the Analyst 1.6.3. software in negative mode (ESI-). The source temperature was $550{ }^{\circ} \mathrm{C}$. From each analyte, the acetate adduct and the deprotonated adduct were scanned.

For the optimization of the separation of DON, D3G, 3ADON and 15ADON, a $1 \mathrm{mg} / \mathrm{L}$ working solution in $\mathrm{ACN} / \mathrm{H}_{2} \mathrm{O}, 40 / 60$, v/v was used. Different UHPLC columns, of C18, perfluorinated and chiral materials were tested for this purpose using two following LC methods, where eluent A was composed of 5\% MeOH (or ACN) and eluent $\mathrm{B}$ of $98 \%$ 
$\mathrm{MeOH}$ (or $\mathrm{ACN}$ ), both containing $2 \mathrm{mM}$ ammonium acetate. Chromatographic separation was performed at $25^{\circ} \mathrm{C}$ with a flow rate of $0.4 \mathrm{~mL} / \mathrm{min}$ for columns with a length of $50 \mathrm{~mm}$, and a flow rate of $0.2 \mathrm{~mL} / \mathrm{min}$ for columns with a length of 100 or $150 \mathrm{~mm}$. The injection volume was set to $3 \mu \mathrm{L}$. The total chromatographic run time was $15 \mathrm{~min}$. Different gradients' initial conditions (10, 20 and 30\% of B) and slopes with an intermediate step at $(20,30,40$ and $50 \%$ B) were tested prior to shortening the method from 15 to 7 min. Tested columns were purchased from Agilent Technologies (Waldbronn, Germany), Daicel (Chiral Technologies Europe SAS, Illkirch-Graffenstaden, France), Phenomenex (Aschaffenburg, Germany), Sigma-Aldrich, ThermoFisher Scientific (Vienna, Austria) or Waters (Vienna, Austria) and are shown in Table 4.

Table 4. Evaluated analytical columns for the LC-MS/MS method.

\begin{tabular}{cccc}
\hline Supplier & Brand Name & Dimensions (mm) & Particle Size $(\mu \mathbf{m})$ \\
\hline Agilent & ZORBAX RRHD Eclipse Plus & $2.1 \times 50$ & 1.8 \\
\hline Agilent & ZORBAX RRHT Extend-C18 & $2.1 \times 50$ & 1.8 \\
\hline Thermo & Hypersil GOLD C18 & $2.1 \times 50$ & 1.9 \\
\hline Waters & ACQUITY UPLC BEH C18 & $2.1 \times 50$ & 1.7 \\
\hline Agilent & ZORBAX RRHD StableBond C18 & $2.1 \times 100$ & 1.8 \\
\hline Agilent & ZORBAX RRHD Eclipse & $2.1 \times 100$ & 1.8 \\
\hline Phenomenex & Kinetex C18 & $2.1 \times 100$ & 2.6 \\
\hline Waters & ACQUITY UPLC HSS T3 (C18) & $2.1 \times 100$ & 2.7 \\
\hline Agilent & InfinityLab Poroshell 120 EC-C18 & $2.1 \times 150$ & 2.6 \\
\hline Phenomenex & Kinetex F5 & $2.1 \times 100$ & 5.0 \\
\hline Sigma- & Discovery HS F5 & $2.1 \times 100$ & 3.0 \\
\hline Aldrich & CHIRALPAK AD-3R & $2.1 \times 150$ & 3.0 \\
\hline Daicel & CHIRALCEL OJ-3R & $2.1 \times 150$ & \\
\hline Daicel & &
\end{tabular}

As DON/D3G as well as 3ADON/15ADON yielded nearly identical peak width, the resolution was calculated with the following equation.

$$
\mathrm{R}_{\mathrm{S}}=\frac{\mathrm{t} 2-\mathrm{t} 1}{\mathrm{w}}
$$

Unconventionally, we used the peak at the half maximum (FWHM) rather than the peak at its baseline for the calculations. The reason for that was to minimize the influence of slightly differently integrated peaks (thus, a potentially differently selected baseline) for the selection of the best-suited stationary phase.

Finally, the chromatographic separation was performed on a Waters Acquity UPLC HSS T3 C18, $1.8 \mu \mathrm{m}, 2.1 \times 100 \mathrm{~mm}$ column at $25^{\circ} \mathrm{C}$ with a flow rate of $0.4 \mathrm{~mL} / \mathrm{min}$ and $3 \mu \mathrm{L}$ injection volume. Eluent A was composed of $5 \% \mathrm{ACN}$ and eluent B of $98 \%$ ACN, both containing $2 \mathrm{mM}$ ammonium acetate. The chromatographic separation of the analytes was achieved in a total run time of $7 \mathrm{~min}$, with a gradient comprising an initial hold time of $0.5 \mathrm{~min}$ at $10 \% \mathrm{~B}$ and a linear gradient to $44 \% \mathrm{~B}$ within $3 \mathrm{~min}$. The gradient was set to $100 \%$ $\mathrm{B}$ afterwards to wash the column till $5.4 \mathrm{~min}$, followed to re-equilibration at $10 \% \mathrm{~B}$ until the end of the run. A switching valve directed the LC flow to the MS from 1.0 to $3.8 \mathrm{~min}$. 


\subsection{Method Validation}

Recovery experiments were performed by spiking blank maize samples $(1.00 \pm 0.01 \mathrm{~g})$ with the appropriate amount of spiking solution of unlabeled mycotoxins at six levels (resulting in expected measurement values of 3, 10, 30, 100, 300 and $1000 \mu \mathrm{g} / \mathrm{L}$ ) in triplicate before extraction. The concentrations of spiking solutions used were $10.0 \mathrm{mg} / \mathrm{L}, 1.00 \mathrm{mg} / \mathrm{L}$ and $100 \mu \mathrm{g} / \mathrm{L}$ of DON, D3G, 3ADON and 15ADON solved in pure ACN. Fifteen mL polypropylene tubes with spiked samples were allowed to rest in the hood overnight at room temperature to allow solvent evaporation and to achieve equilibrium between the analytes and matrix. On the next day, the samples were extracted with $4.00 \mathrm{~mL} \mathrm{ACN} / \mathrm{H}_{2} \mathrm{O}$, $20 / 80(v / v)$ for $60 \mathrm{~min}$ on a shaker at room temperature and centrifuged (3500 rpm). Subsequently, $20 \mu \mathrm{L}$ of IS working solution consisting of a $500 \mu \mathrm{g} / \mathrm{L}$ concentration of ${ }^{13} \mathrm{C}$-DON, ${ }^{13} \mathrm{C}-\mathrm{D} 3 \mathrm{G},{ }^{13} \mathrm{C}-3 \mathrm{ADON}$ and ${ }^{13} \mathrm{C}-15 \mathrm{ADON}$ dissolved in $\mathrm{ACN} / \mathrm{H}_{2} \mathrm{O}, 20: 80, v / v$, was added to $80 \mu \mathrm{L}$ of the supernatant in an HPLC vial fitted with a $200 \mu \mathrm{L}$ conical glass insert.

To evaluate matrix effects, blank maize samples $(5.00 \pm 0.01 \mathrm{~g})$ were extracted in triplicates with $20 \mathrm{~mL}$ of $\mathrm{ACN} / \mathrm{H}_{2} \mathrm{O}, 20 / 80(v / v)$ for $60 \mathrm{~min}$ on a rotary shaker $(200 \mathrm{rpm})$ at room temperature and centrifuged $(3500 \mathrm{rpm})$. Matrix-matched standards were prepared at six levels (+a blank level) in triplicates. For this purpose, working standard solutions of mycotoxins were pipetted into HPLC vials, evaporated and reconstituted with $500 \mu \mathrm{L}$ of raw extract. This resulted in a spiking level of 0, 3.00, 10.0, 30.0, 100, 300 and $1000 \mu \mathrm{g} / \mathrm{L}$. Afterwards, $80 \mu \mathrm{L}$ of these solutions were mixed with $20 \mu \mathrm{L}$ IS working solution in an HPLC vial containing a microinsert.

Sample preparation in general consisted of cereal extraction with the four-fold volume of $\mathrm{ACN} / \mathrm{H}_{2} \mathrm{O}, 20 / 80(v / v)$ for $60 \mathrm{~min}$ on a rotary shaker, followed by centrifugation. Always, $80 \mu \mathrm{L}$ of either raw extracts or standard solutions in neat solvents were diluted with $20 \mu \mathrm{L}$ IS solution (500 $\mu \mathrm{g} / \mathrm{L}$ of all four labelled compounds) directly in the HPLC microinsert prior to analysis.

\subsection{Data Evaluation}

For data evaluation, $1 / \times$ weighted calibration curves were obtained for each analyte by plotting the relative response versus the analyte concentration using Analyst 1.6.3 (Sciex, Concord, ON, Canada) software. The peak area of the analyte divided by the peak area of the corresponding internal standard was the relative response. The analytes concentrations were calculated by the relative response and the calibration curves with internal calibration. Apparent recoveries were calculated by the ratio of measured to spiked concentrations, followed by calculating the average value of all six spiking levels in triplicate analysis, expressed in percent.

For the evaluation of matrix effects, the data were first analyzed without considering the internal standards, which led to the determination of the apparent recoveries for external calibration. Furthermore, signal suppression or enhancement (SSE) of the SIDA method was calculated from the spiked blank extracts in the same way. To calculate the extraction recovery $\left(\mathrm{R}_{\mathrm{E}}\right)$, mean values of the apparent recovery using internal calibration $\left(\mathrm{R}_{\mathrm{A}}\right)$ were divided by the mean values of the signal suppression or enhancement (SSE). The repeatability $\left(\mathrm{RSD}_{\mathrm{r}}\right)$ was calculated from the triplicate analysis at seven spiking levels.

Author Contributions: Conceptualization, G.A. and F.B.; methodology, I.F., H.M. and F.B.; validation, I.F. and F.B.; data curation, I.F. and M.M.S.; writing-original draft preparation, M.M.S. and F.B.; writing-review and editing, H.M. and G.A.; supervision, G.A. and F.B.; project administration and funding acquisition, G.A. and F.B. All authors have read and agreed to the published version of the manuscript.

Funding: This research was funded by the Vienna Science and Technology Fund (WWTF LS12-021), the Austrian Science Fund (FWF; SFB F3706, F3708, and F3715) and Romer Labs (Tulln, Austria). Furthermore, financial support by the Austrian Federal Ministry of Science, Research and Economy, 
the National Foundation for Research, Technology and Development, and BIOMIN Holding GmbH is acknowledged for funding the Christian Doppler Laboratory for Mycotoxin Metabolism.

Institutional Review Board Statement: Not applicable.

Informed Consent Statement: Not applicable.

Acknowledgments: We are grateful to DI Georg Häubl, Lilian Kuster and Ing. Günther Jaunecker (all Romer Labs, Tulln, Austria) for their support in the production and purification of ${ }^{13} \mathrm{C}-\mathrm{D} 3 \mathrm{G}$. Open Access Funding by the Austrian Science Fund (FWF).

Conflicts of Interest: The authors declare no conflict of interest. The funders had no role in the design of the study; in the collection, analyses, or interpretation of data; in the writing of the manuscript, or in the decision to publish the results.

\section{References}

1. Alshannaq, A.; Yu, J.-H. Occurrence, Toxicity, and Analysis of Major Mycotoxins in Food. Int. J. Environ. Res. Public Health 2017, 14, 632. [CrossRef]

2. McCormick, S.P.; Stanley, A.M.; Stover, N.A.; Alexander, N.J. Trichothecenes: From Simple to Complex Mycotoxins. Toxins 2011, 3, 802-814. [CrossRef]

3. Ma, L.-J.; Geiser, D.M.; Proctor, R.H.; Rooney, A.P.; O’Donnell, K.; Trail, F.; Gardiner, D.M.; Manners, J.M.; Kazan, K. FusariumPathogenomics. Annu. Rev. Microbiol. 2013, 67, 399-416. [CrossRef]

4. Khaneghah, A.M.; Fakhri, Y.; Raeisi, S.; Armoon, B.; Sant'Ana, A.S. Prevalence and concentration of ochratoxin A, zearalenone, deoxynivalenol and total aflatoxin in cereal-based products: A systematic review and meta-analysis. Food Chem. Toxicol. 2018, 118, 830-848. [CrossRef]

5. Pestka, J.J. Deoxynivalenol: Mechanisms of action, human exposure, and toxicological relevance. Arch. Toxicol. 2010, 84, 663-679. [CrossRef]

6. Berthiller, F.; Dall'Asta, C.; Corradini, R.; Marchelli, R.; Sulyok, M.; Krska, R.; Adam, G.; Schuhmacher, R. Occurrence of deoxynivalenol and its 3- $\beta$-D-glucoside in wheat and maize. Food Addit. Contam. Part A 2009, 26, 507-511. [CrossRef]

7. Varga, E.; Malachova, A.; Schwartz, H.; Krska, R.; Berthiller, F. Survey of deoxynivalenol and its conjugates deoxynivalenol-3glucoside and 3-acetyl-deoxynivalenol in 374 beer samples. Food Addit. Contam. Part A 2013, 30, 137-146. [CrossRef]

8. Payros, D.; Alassane-Kpembi, I.; Pierron, A.; Loiseau, N.; Pinton, P.; Oswald, I.P. Toxicology of deoxynivalenol and its acetylated and modified forms. Arch. Toxicol. 2016, 90, 2931-2957. [CrossRef]

9. Rychlik, M.; Humpf, H.-U.; Marko, D.; Dänicke, S.; Mally, A.; Berthiller, F.; Klaffke, H.; Lorenz, N. Proposal of a comprehensive definition of modified and other forms of mycotoxins including "masked" mycotoxins. Mycotoxin Res. 2014, 30, 197-205. [CrossRef]

10. EFSA Panel on Contaminants in the Food Chain. Risks to human and animal health related to the presence of deoxynivalenol and its acetylated and modified forms in food and feed. EFSA J. 2017, 15, e04718. [CrossRef]

11. Tittlemier, S.; Cramer, B.; Dall'Asta, C.; Iha, M.; Lattanzio, V.; Maragos, C.; Solfrizzo, M.; Stranska, M.; Stroka, J.; Sumarah, M. Developments in mycotoxin analysis: An update for 2018-2019. World Mycotoxin J. 2020, 13, 3-24. [CrossRef]

12. Tittlemier, S.; Brunkhorst, J.; Cramer, B.; DeRosa, M.; Lattanzio, V.; Malone, R.; Maragos, C.; Stranska, M.; Sumarah, M. Developments in mycotoxin analysis: An update for 2019-2020. World Mycotoxin J. 2021, 14, 3-26. [CrossRef]

13. Malachová, A.; Stránská, M.; Václavíková, M.; Elliott, C.T.; Black, C.; Meneely, J.; Hajslova, J.; Ezekiel, C.N.; Schuhmacher, R.; Krska, R. Advanced LC-MS-based methods to study the co-occurrence and metabolization of multiple mycotoxins in cereals and cereal-based food. Anal. Bioanal. Chem. 2018, 410, 801-825. [CrossRef]

14. Li, P.; Zhang, Z.; Hu, X.; Zhang, Q. Advanced hyphenated chromatographic-mass spectrometry in mycotoxin determination: Current status and prospects. Mass Spectrom. Rev. 2013, 32, 420-452. [CrossRef]

15. Häubl, G.; Berthiller, F.; Krska, R.; Schuhmacher, R. Suitability of a fully 13C isotope labeled internal standard for the determination of the mycotoxin deoxynivalenol by LC-MS/MS without clean up. Anal. Bioanal. Chem. 2006, 384, 692-696. [CrossRef]

16. Varga, E.; Glauner, T.; Köppen, R.; Mayer, K.; Sulyok, M.; Schuhmacher, R.; Krska, R.; Berthiller, F. Stable isotope dilution assay for the accurate determination of mycotoxins in maize by UHPLC-MS/MS. Anal. Bioanal. Chem. 2012, 402, 2675-2686. [CrossRef]

17. Habler, K.; Rychlik, M. Multi-mycotoxin stable isotope dilution LC-MS/MS method for Fusarium toxins in cereals. Anal. Bioanal. Chem. 2015, 408, 307-317. [CrossRef]

18. Habler, K.; Frank, O.; Rychlik, M. Chemical Synthesis of Deoxynivalenol-3- $\beta-D-\left[13 C_{6}\right]$-glucoside and Application in Stable Isotope Dilution Assays. Molecules 2016, 21, 838. [CrossRef] [PubMed]

19. Malachová, A.; Sulyok, M.; Beltran, E.; Berthiller, F.; Krska, R. Optimization and validation of a quantitative liquid chromatography-tandem mass spectrometric method covering 295 bacterial and fungal metabolites including all regulated mycotoxins in four model food matrices. J. Chromatogr. A 2014, 1362, 145-156. [CrossRef]

20. Michlmayr, H.; Malachová, A.; Varga, E.; Kleinová, J.; Lemmens, M.; Newmister, S.; Rayment, I.; Berthiller, F.; Adam, G. Biochemical Characterization of a Recombinant UDP-glucosyltransferase from Rice and Enzymatic Production of Deoxynivalenol3-O- $\beta$-d-glucoside. Toxins 2015, 7, 2685-2700. [CrossRef] [PubMed] 
21. Josephs, R.; Krska, R.; Grasserbauer, M.; Broekaert, J. Determination of trichothecene mycotoxins in wheat by use of supercritical fluid extraction and high-performance liquid chromatography with diode array detection or gas chromatography with electron capture detection. J. Chromatogr. A 1998, 795, 297-304. [CrossRef]

22. Buttinger, G.; Krska, R. Determination of B-trichothecenes in wheat by post column derivatisation liquid chromatography with fluorescence detection (PCD-HPLC-FLD). Mycotoxin Res. 2003, 19, 139-143. [CrossRef]

23. Polak-Śliwińska, M.; Paszczyk, B. Trichothecenes in Food and Feed, Relevance to Human and Animal Health and Methods of Detection: A Systematic Review. Molecules 2021, 26, 454. [CrossRef]

24. European Commission. Commission Regulation (EC) No 1881/2006 of 19 December 2006. Setting maximum levels for certain contaminants in foodstuffs. Off. J. Eur. Union 2006, 364, 5-24.

25. Horwitz, W. Evaluation of Analytical Methods Used for Regulation of Foods and Drugs. Anal. Chem. 1982, 54, 67A-76A. [CrossRef] 